\title{
A hesitant fuzzy linguistic term sets-based AHP approach for analyzing the performance evaluation factors: an application to cargo sector
}

\author{
Fatih Tüysüz $^{1}$ - Berna Şimşek ${ }^{2}$
}

Received: 7 February 2017 / Accepted: 26 April 2017 / Published online: 9 May 2017

(C) The Author(s) 2017. This article is an open access publication

\begin{abstract}
One of the important points in performance measurement and evaluation is determining the relative importance of the metrics used. The aim of this study is to present a fuzzy multi-criteria decision-making approach for evaluating the factors used for performance evaluation. Hesitant fuzzy sets-based analytic hierarchy process method, which is an effective and successful approach to deal with uncertainty, is proposed for analyzing the factors affecting the performance of the branches of a cargo company in Turkey and also for prioritizing them according to their level of importance.
\end{abstract}

Keywords Performance evaluation $\cdot$ Cargo sector $\cdot$ Hesitant AHP

\section{Introduction}

Logistics can be defined as a collection of dynamic activities which forms the connection between production and consumption [1]. Cargo sector is a fast growing and highly competitive sector which performs complex logistic activities and it serves both individuals and business firms for transportation and transshipment. Most of the global cargo firms adopt the strategy of locating different distribution centers for collecting cargos from their branches and then transshipping them through different modes of transporta-

Fatih Tüysüz

fatih.tuysuz@istanbul.edu.tr

Berna Şimşek

bernasimsek89@gmail.com

1 Department of Industrial Engineering, İstanbul University, Istanbul 34320, Turkey

2 Graduate School (Institute) of Science, İstanbul University, Istanbul 34320, Turkey tion to other transfer centers. These cargos are then delivered to final destination through the branches of the firm within the customers' region [2]. Most of the cargo firms provide their organizational customers third party logistics services and play an important role in their competitive advantage by creating value [3] which enable these customers to reduce costs and focus on their core activities [4,5]. Prajogo et al. [6] studied the multidimensional relationships between supplier management practices and firm operational performance. They presented the relative contributions of different kinds of supplier management to different performance measures and found that both strategic long-term relationship and logistics integration have positive relationships with delivery, flexibility, and cost performance. Since cargo firms have diversified customers, it can be said that the cargo firms play a critical role especially on the success of their customers' operations.

One of the most important performance measures for cargo firms is the delivery of the cargos on time with the minimum cost. They try to decrease the transportation costs while trying to minimize the distance travelled and the duration of travel for cargos. The branches within the customer regions are the first contact points with the customers and have important effect on customer satisfaction. The success of cargo firms in such a competitive environment mainly depends on the performance of these branches. A good performance measurement and evaluation system enables organizations to better understand and evaluate their operations and may provide competitive advantage [7]. It has also important contribution to the effective control of business progress by enhancing the overall efficiency and profitability [8].

Since cargo business is complex, performance measurement and evaluation can be performed in different ways. There are different methods and developed models for performance evaluation. Ozcan and Tuysuz [9] present a detailed literature review related to performance measure-

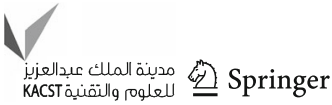


ment, and state that data envelopment analysis (DEA) and multi-criteria methods are the most widely used ones. Due to the reason that performance measurement and evaluation require more than one dimension to be considered, it can be handled as a multiple criteria decision-making (MCDM) problem.

Multi-criteria decision-making (MCDM) methods enable the decision-makers handle uncertainty, complexity and conflicting objectives. MCDM problems usually require both tangible and intangible factors to be evaluated. The main problem for intangible criteria is that the values for such criteria are often imprecisely defined for the decision-makers. and the desired value for the criteria are usually defined in linguistic terms. It is difficult to express the character and significance of criteria exactly or clearly in crisp methods [10]. The conventional approaches tend to be less effective in dealing with the imprecision or vague nature of the linguistic assessment [11-13]. Due to this reason, the use of the fuzzy set theory in MCDM for evaluating various factors and alternatives seems more convenient by allowing decision-makers to express their ideas more adequately [14].

The most recent studies in literature related to performance measurement in logistics by using MCDM methods can be summarized as follows.

Kayakutlu and Buyukozkan [15] present an analytical framework to assess the performance factors for third party logistics companies through a managerial view. The factors integrating the strategical and operational targets are evaluated within a framework based on four levels: performance targets, planning activities, logistics operations, and performance attributes of logistics operations. The ANP method is used to determine the most effective performance attributes.

Zhang and Tan [16] present a performance evaluation index system based on AHP method which is especially suitable for the small and medium third party logistics enterprise from the four levels of financial, customers, business and innovation.

Shaik and Abdul-Kader [17] develop a comprehensive reverse logistics performance measurement model by integrating balanced scorecard (BSC) and performance prism. They use decision-making trial and evaluation laboratory (DEMATEL) method for investigating the cause and effect relationship of the performance measurement attributes and factors.

da Silveira Guimarães and Salomon [18] apply ANP method for the evaluation of the priority order of reverse logistics indicators in a small company.

Kucukaltan et al. [19] present a decision support model for identification and prioritization of KPIs in the logistics industry. They apply BSC and analytic network process (ANP) methods in combination to evaluate logistics performance indicators.
Özceylan et al. [20] propose a GIS-based multi-criteria decision analysis approach for the logistics performance evaluation of provinces in Turkey. They use AHP, ANP and TOPSIS methods prioritizing the indicators and ranking the provinces.

Performance indicators (PIs) and key performance indicators (KPIs) are two important concepts in performance measurement. PIs are the quantifiable metrics used for evaluating the performance actions, whereas KPIs, which are also PIs, are applied to the important or critical actions [21]. The determination of the KPIs among PIs is a classification or prioritization problem which is based on revealing the relative importance of these metrics. In this study, we present a fuzzy MCDM approach for analyzing and evaluating the factors affecting the performance of the branches of a cargo company. Since the integration of hesitant fuzzy sets (HFSs) [22] with analytic hierarchy process (AHP) [23] method seems an effective and successful approach to deal with uncertainty, HFSs-based AHP is proposed for analyzing the factors affecting the performance of the branches and also for prioritizing them according to their level of importance.

The organization of the paper is as follows. In the following section, hesitant fuzzy sets and hesitant fuzzy AHP method used in the study are presented. In the next section, application of hesitant fuzzy AHP for evaluating the factors affecting performance evaluation of the branches of a cargo company in Turkey is given. Finally, the conclusions are presented.

\section{Hesitant fuzzy sets and hesitant fuzzy AHP}

Hesitant fuzzy sets (HFSs) developed by Torra [22] are the extensions of regular fuzzy sets and this theory allows the membership degrees to have a set of possible values between 0 and 1 [24]. The main idea behind the usage of HFS in decision-making is that when more than one decision-makers assign membership degree of an element to a set, the difficulty of establishing a common membership degree arises. Since people may have hesitancy in providing their preferences, HFS can be effectively used to represent these in different levels of decision-making process.

Let $X$ be a fixed set, an HFS on $X$ is in terms of a function that when applied to $X$ returns a subset of $[0,1]$. Mathematical expression for HFS is

$E=\left\{\left\langle x, h_{E}(x)\right\rangle \mid x \in X\right\}$,

where $h_{E}(x)$ is a set of some values in $[0,1]$, denoting the possible membership degrees of the element $x \in X$ to the set $E$, and $h=h_{E}(x)$ is a hesitant fuzzy element (HFE). 
Let $h, h_{1}$ and $h_{2}$ be three HFEs, then basic operations on these elements are defined as follows:

$h^{-}(x)=\min h(x)$

$h^{+}(x)=\max h(x)$,

where $h^{-}(x)$ and $h^{+}(x)$ are the lower and upper bounds of $h$, respectively.

$h^{c}=\cup_{\gamma \in h}\{1-\gamma\}$,

where $h^{c}$ is the complement of $h$.

$$
\begin{aligned}
& h^{\lambda}=\cup_{\gamma \in h}\left\{\gamma^{\lambda}\right\} \\
& \lambda h=\cup_{\gamma \in h}\left\{1-(1-\gamma)^{\lambda}\right\} \\
& h_{1} \bigcup h_{2}=\cup_{\gamma_{1} \in h_{1}, \gamma_{2} \in h_{2}}, \quad \max \left\{\gamma_{1}, \gamma_{2}\right\} \\
& h_{1} \cap h_{2}=\cup_{\gamma_{1} \in h_{1}, \gamma_{2} \in h_{2}}, \quad \min \left\{\gamma_{1}, \gamma_{2}\right\} \\
& h_{1} \oplus h_{2}=\cup_{\gamma_{1} \in h_{1}, \gamma_{2} \in h_{2}},\left\{\gamma_{1}+\gamma_{2}-\gamma_{1} \gamma_{2}\right\} \\
& h_{1} \oplus h_{2}=\cup_{\gamma_{1} \in h_{1}, \gamma_{2} \in h_{2}},\left\{\gamma_{1} \gamma_{2}\right\}
\end{aligned}
$$

AHP is one of the most widely used MCDM methods due to the reasons that it enables to handle both tangibles and intangibles and also its simple mathematical calculations. AHP incorporates the evaluations of all decision-makers into a final decision, without having to elicit their utility functions on subjective and objective criteria, by pairwise comparisons of alternatives.

AHP method uses crisp or objective mathematics to represent the subjective or personal preferences of an individual or a group in MCDM [25]. One of the important drawbacks of classical or crisp AHP is that it cannot adequately handle the inherent uncertainty and vagueness [26]. In classical AHP, the pairwise comparisons are performed by using the crisp numbers within the 1-9 scale. In real life problems, the decision-makers may be unable to assign the crisp evaluation values to the comparison judgments due to the limited knowledge or the subjectivity of the qualitative evaluation criteria or the variations of individual judgments in group decision-making [27]. Since decision-makers' evaluations in pairwise comparisons contain uncertainty, this may cause the decision-makers feel more confident to provide fuzzy judgement than crisp comparisons [28]. In order to overcome above-mentioned disadvantages of crisp AHP, the fuzzy sets theory is the most convenient and mostly applied approach.

Fuzzy extensions of AHP are usually in the form of fuzzifying the pairwise comparisons by using fuzzy numbers. Fuzzy AHP is an extension of crisp AHP in which fuzzy sets are incorporated with the pairwise comparisons to model the uncertainty in human judgment and preference. These extensions can be classified as ordinary fuzzy sets, type-2 fuzzy sets, intuitionistic fuzzy sets (IFS), and hesitant fuzzy sets (HFS) [29].

HFS extensions of AHP method and their applications in literature can be summarized as follows.

Mousavi et al. [30] propose a method called hesitant fuzzy AHP (HF-AHP) in which decision-makers' (DMs) evaluations for comparison matrices are expressed by linguistic variables and then judgments are aggregated by utilizing the hesitant fuzzy geometric operator.

Zhu and Xu [31] propose a methodology called AHPhesitant group decision-making (AHP-HGDM). They introduce multiplicative preference relations (HMPRs) to collect the hesitant judgments, and a hesitant multiplicative programming method (HMPM) as a new prioritization method to derive priorities from HMPRs.

Zhu et al. [32] develop a new prioritization method called hesitant preference analysis and propose a hesitant AHP $(\mathrm{H}-$ AHP) method as an extension of traditional AHP.

Öztaysi et al. [33] develop a hesitant fuzzy AHP method involving multi-experts' linguistic evaluations aggregated by ordered weighted averaging (OWA) operator. They also apply their method to a multi-criteria supplier selection problem.

Onar et al. [34] propose a new hesitant fuzzy quality function deployment (QFD) approach for selection of computer workstation. QFD is used to define design requirements of computer workstation. They use hesitant fuzzy AHP method to determine weights of criteria and use hesitant fuzzy technique for order performance by similarity to ideal solution (TOPSIS) method to select the most suitable alternative.

Zhou and Xu [35] introduce the hesitant fuzzy preference format and define the hesitant fuzzy continuous preference term. Based on this approach, the asymmetric hesitant fuzzy sigmoid preference relation (AHSPR) is developed and used in the AHP. They also present a model framework of the AHSPR in the AHP and give a numerical example in order to demonstrate the application and advantages of the proposed numerical scale, the preference format, and the modeling framework.

Rodriguez et al. [36] present a different approach named as hesitant fuzzy linguistic term set (HFLTS) to handle the hesitation of DMs. The importance of this approach is that it provides a linguistic and computational basis for the use of context-free grammars by using comparative terms.

Rodriguez et al. [37] propose a new group decision model based on HFLTS in order to enhance the elicitation of flexible and rich linguistic expressions. Their model considers only single criterion and cannot be used for complex MCDM problems.

Yavuz et al. [38] extend HFLTS to multi-criteria evaluation which considers hesitancy of the experts in defining membership degrees or functions. They use linguistic term sets together with context-free grammar. This model can handle

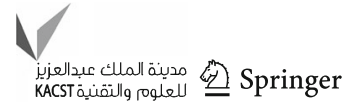


Fig. 1 Hierarchy of the MCDM model for the evaluation of factors affecting the overall performance

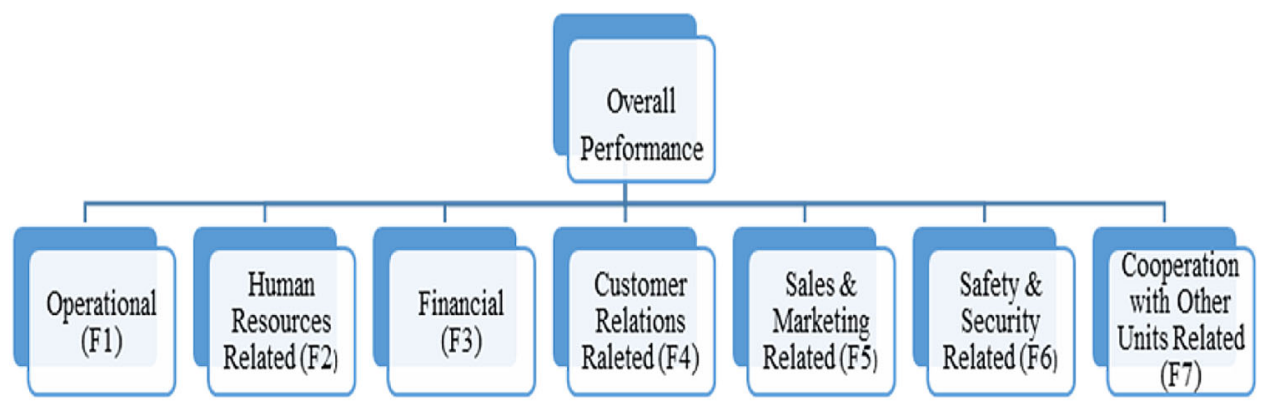

a complex MCDM problem with a hierarchical structure and use a fuzzy representation for comparative linguistic expressions based on a fuzzy envelope for HFLTS.

Some other important studies related to the use of hesitant sets in multi-criteria group decision-making can be found in [39-41].

In this study, HFLTS-based AHP method is used due to the reason that HFLTS enable to mathematically represent and solve decision-making problems with multiple linguistic assessments and enhance the elicitation of flexible and rich linguistic expressions.

Before we present the HFLTS-based AHP methodology, some basic concepts related to HFLTS will be given.

Definition 1 An HFLTS, $H_{s}$, is an ordered finite subset of consecutive linguistic terms of a linguistic term set $S$ which can be shown as $S=\left\{s_{0}, s_{1}, \ldots, s_{g}\right\}$.

Definition 2 Assume that $E_{G_{H}}$ is a function that converts linguistic expressions into HFLTS, $H_{S}$. Let $G_{H}$ be a contextfree grammar that uses the linguistic term set $S$. Let $S_{l l}$ be the expression domain generated by $G_{H}$. This relation can be shown as $E_{G_{H}}: S_{l l} \rightarrow H_{S}$.

Using the following transformations comparative linguistic expressions are converted into HFLTSs:

$E_{G_{H}}\left(s_{i}\right)=\left\{s_{i} \mid s_{i} \in S\right\}$

$E_{G_{H}}\left(\right.$ at most $\left.s_{i}\right)=\left\{s_{j} \mid s_{j} \in S\right.$ and $\left.s_{j} \leq s_{i}\right\}$

$E_{G_{H}}$ (lower than $\left.s_{i}\right)=\left\{s_{j} \mid s_{j} \in S\right.$ and $\left.s_{j}<s_{i}\right\}$

$E_{G_{H}}\left(\right.$ at least $\left.s_{i}\right)=\left\{s_{j} \mid s_{j} \in S\right.$ and $\left.s_{j} \geq s_{i}\right\}$

$E_{G_{H}}\left(\right.$ greater than $\left.s_{i}\right)=\left\{s_{j} \mid s_{j} \in S\right.$ and $\left.s_{j}>s_{i}\right\}$

$E_{G_{H}}\left(\right.$ between $s_{i}$ and $\left.s_{j}\right)=\left\{s_{k} \mid s_{k} \in S\right.$ and $\left.s_{i} \leq s_{k} \leq s_{j}\right\}$.

Definition 3 The envelope of an HFLTS is represented by env $\left(H_{S}\right)$, and it is a linguistic interval whose limits are obtained by its maximum value and minimum value,

$\operatorname{env}\left(H_{S}\right)=\left[H_{S^{-}}, H_{S^{+}}\right], H_{S^{-}} \leq H_{S^{+}}$, where

$H_{S^{-}}=\min \left(s_{i}\right)=s_{j}, s_{i} \in H_{S}$ and $s_{i} s_{j} \forall i$

$H_{S^{+}}=\max \left(s_{i}\right)=s_{j}, s_{i} \in H_{S}$ and $s_{i} \leq s_{j} \forall i$.

The algorithmic steps of the HFLTS-based AHP $[33,38]$ method used in this study are as follows:

Step 1 Define the semantics and syntax of the linguistic term set $S$ and the context-free grammar $G_{H}$, where $G_{H}=\left\{V_{N}, V_{T}, I, P\right\}$

$V_{N}=\left\{\begin{array}{c}\langle\text { primary term }\rangle,\langle\text { composite term }\rangle,\langle\text { unary relation }\rangle, \\ \langle\text { binary relation }\rangle,\langle\text { conjunction }\rangle\end{array}\right\}$

$V_{T}=\{$ lower than, greater than, at least, at most, between, and, $\left.\mathrm{s}_{0}, s_{1}, \ldots, s_{g}\right\}$

$I \in V_{N}$

The production rules can be obtained by Eq. (19).

$P=\left\{\begin{array}{l}I::=\langle\text { primary term }\rangle \mid\langle\text { composite term }\rangle, \\ \langle\text { composite term }\rangle::= \\ \langle\text { unary relation }\rangle\langle\text { primary term }\rangle \mid \\ \langle\text { binary relation }\rangle\langle\text { primary term }\rangle\langle\text { conjunction }\rangle\langle\text { primary term }\rangle, \\ \langle\text { primary term }\rangle::=s_{0}\left|s_{1}\right| \ldots \mid s_{g}, \\ \langle\text { unary relation }\rangle::=\text { lower than } \mid \text { greater than } \mid \text { at least } \mid \text { at most, } \\ \langle\text { binary relation }\rangle::=\text { between, } \quad\langle\text { conjunction }\rangle::=\text { and }\end{array}\right\}$

Step 2 Gather the pairwise comparisons from the experts. In the domain of group decision-making, $m$ decision-makers ( $\left.E=\left\{e_{1}, e_{2}, \ldots, e_{m}\right\}\right)$ try to select the best alternative among $n$ alternatives $\left(X=\left\{x_{1}, x_{2}, \ldots, x_{n}\right\}\right)$, where $m>1$ and $n>1$. In this case, a matrix composed of preference relations $\left(p^{k} s\right)$ are formed as given in Eq. (20).

$p^{k}=\left(\begin{array}{lll}p_{11}^{k} & \cdots & p_{1 m}^{k} \\ \vdots & \ddots & \vdots \\ p_{n 1}^{k} & \cdots & p_{n m}^{k}\end{array}\right)$ 


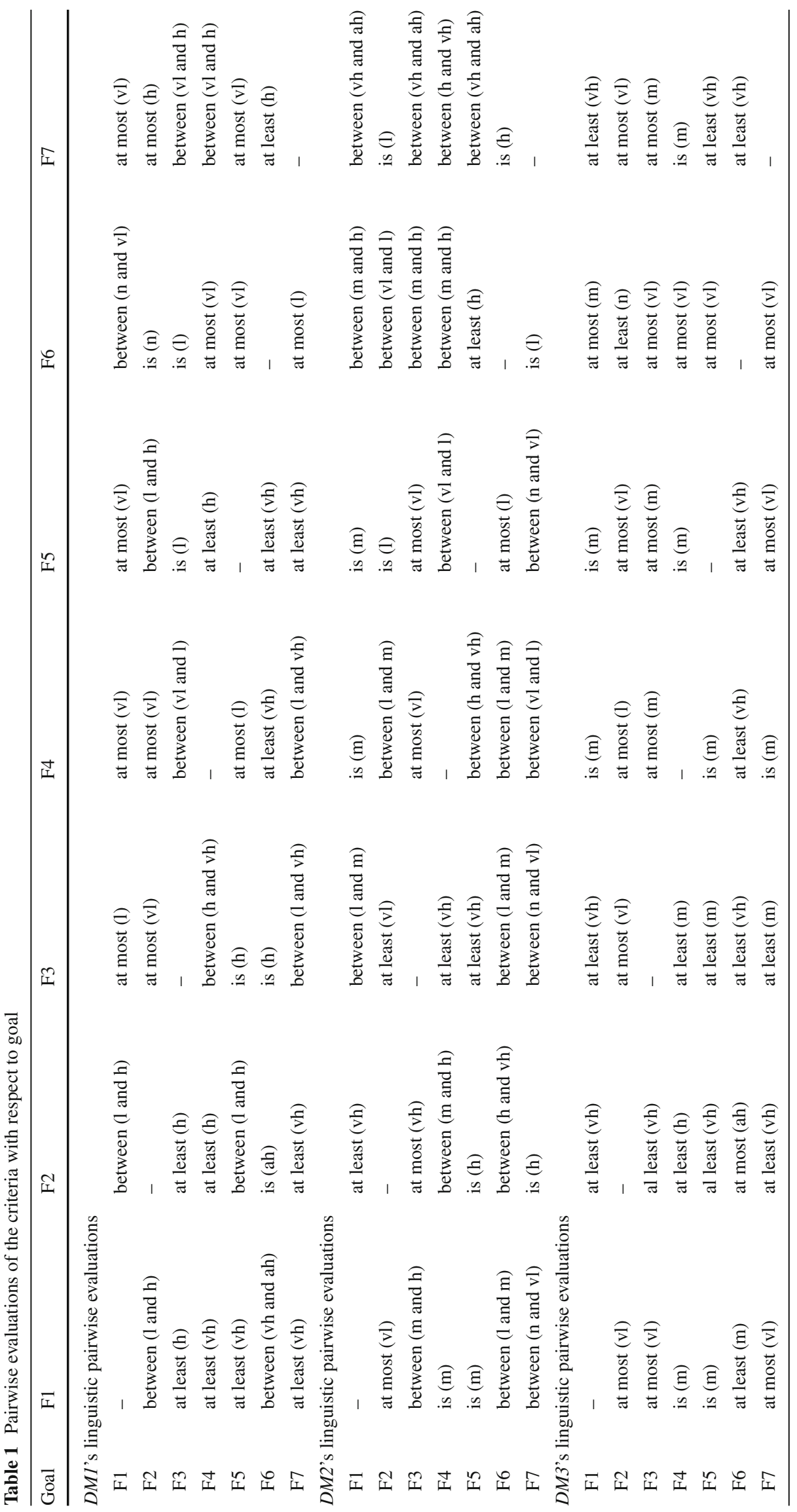


Table 2 Obtained envelops for the HFLTS given in Table 1

\begin{tabular}{|c|c|c|c|c|c|c|c|}
\hline Goal & $\mathrm{F} 1$ & $\mathrm{~F} 2$ & F3 & F4 & F5 & F6 & F7 \\
\hline \multicolumn{8}{|c|}{ HFLTS intervals for $D M 1$ 's evaluations } \\
\hline $\mathrm{F} 1$ & - & {$[1, \mathrm{~h}]$} & {$[\mathrm{n}, 1]$} & {$[\mathrm{n}, \mathrm{vl}]$} & {$[\mathrm{n}, \mathrm{vl}]$} & {$[\mathrm{n}, \mathrm{vl}]$} & {$[\mathrm{n}, \mathrm{vl}]$} \\
\hline $\mathrm{F} 2$ & {$[1, \mathrm{~h}]$} & - & {$[\mathrm{n}, \mathrm{vl}]$} & {$[\mathrm{n}, \mathrm{vl}]$} & {$[1, \mathrm{~h}]$} & {$[\mathrm{n}, \mathrm{n}]$} & {$[\mathrm{n}, \mathrm{h}]$} \\
\hline $\mathrm{F} 3$ & {$[\mathrm{~h}, \mathrm{ah}]$} & {$[\mathrm{h}, \mathrm{ah}]$} & - & {$[\mathrm{vl}, 1]$} & {$[1,1]$} & {$[1,1]$} & {$[\mathrm{vl}, \mathrm{h}]$} \\
\hline $\mathrm{F} 4$ & {$[\mathrm{vh}, \mathrm{ah}]$} & {$[\mathrm{h}, \mathrm{ah}]$} & {$[\mathrm{h}, \mathrm{ah}]$} & - & {$[\mathrm{h}, \mathrm{ah}]$} & {$[\mathrm{n}, \mathrm{vl}]$} & {$[\mathrm{vl}, \mathrm{h}]$} \\
\hline F5 & {$[\mathrm{vh}, \mathrm{ah}]$} & {$[1, \mathrm{~h}]$} & {$[\mathrm{h}, \mathrm{h}]$} & {$[\mathrm{n}, 1]$} & - & {$[\mathrm{n}, \mathrm{vl}]$} & {$[\mathrm{n}, \mathrm{vl}]$} \\
\hline F6 & {$[\mathrm{vh}, \mathrm{ah}]$} & {$[\mathrm{ah}, \mathrm{ah}]$} & {$[\mathrm{h}, \mathrm{h}]$} & {$[\mathrm{vh}, \mathrm{ah}]$} & {$[\mathrm{vh}, \mathrm{ah}]$} & - & {$[\mathrm{h}, \mathrm{ah}]$} \\
\hline F7 & {$[\mathrm{vh}, \mathrm{ah}]$} & {$[\mathrm{vh}, \mathrm{ah}]$} & {$[1, \mathrm{vh}]$} & {$[1, \mathrm{vh}]$} & {$[\mathrm{vh}, \mathrm{ah}]$} & {$[\mathrm{n}, 1]$} & - \\
\hline \multicolumn{8}{|c|}{ HFLTS intervals for $D M 2$ 's evaluations } \\
\hline $\mathrm{F} 1$ & - & {$[\mathrm{vh}, \mathrm{ah}]$} & {$[1, \mathrm{~m}]$} & {$[\mathrm{m}, \mathrm{m}]$} & {$[\mathrm{m}, \mathrm{m}]$} & {$[\mathrm{m}, \mathrm{h}]$} & {$[\mathrm{vh}, \mathrm{ah}]$} \\
\hline $\mathrm{F} 2$ & {$[\mathrm{n}, \mathrm{vl}]$} & - & {$[\mathrm{vl}, \mathrm{ah}]$} & {$[1, \mathrm{~m}]$} & {$[1,1]$} & {$[\mathrm{vl}, 1]$} & {$[1,1]$} \\
\hline $\mathrm{F} 3$ & {$[\mathrm{~m}, \mathrm{~h}]$} & {$[\mathrm{n}, \mathrm{vh}]$} & - & {$[\mathrm{n}, \mathrm{vl}]$} & {$[\mathrm{n}, \mathrm{vl}]$} & {$[\mathrm{m}, \mathrm{h}]$} & {$[\mathrm{vh}, \mathrm{ah}]$} \\
\hline $\mathrm{F} 4$ & {$[\mathrm{~m}, \mathrm{~m}]$} & {$[\mathrm{m}, \mathrm{h}]$} & {$[\mathrm{vh}, \mathrm{ah}]$} & - & {$[\mathrm{vl}, 1]$} & {$[\mathrm{m}, \mathrm{h}]$} & {$[\mathrm{h}, \mathrm{vh}]$} \\
\hline F5 & {$[\mathrm{m}, \mathrm{m}]$} & {$[\mathrm{h}, \mathrm{h}]$} & {$[\mathrm{vh}, \mathrm{ah}]$} & {$[\mathrm{h}, \mathrm{vh}]$} & - & {$[\mathrm{h}, \mathrm{ah}]$} & {$[\mathrm{vh}, \mathrm{ah}]$} \\
\hline F6 & {$[1, \mathrm{~m}]$} & {$[\mathrm{h}, \mathrm{vh}]$} & {$[1, \mathrm{~m}]$} & {$[1, \mathrm{~m}]$} & {$[\mathrm{n}, 1]$} & - & {$[\mathrm{h}, \mathrm{h}]$} \\
\hline F7 & {$[\mathrm{n}, \mathrm{vl}]$} & {$[\mathrm{h}, \mathrm{h}]$} & {$[\mathrm{n}, \mathrm{vl}]$} & {$[\mathrm{vl}, 1]$} & {$[\mathrm{n}, \mathrm{vl}]$} & {$[1,1]$} & - \\
\hline \multicolumn{8}{|c|}{ HFLTS intervals for $D M 3$ 's evaluations } \\
\hline $\mathrm{F} 1$ & - & {$[\mathrm{vh}, \mathrm{ah}]$} & {$[\mathrm{vh}, \mathrm{ah}]$} & {$[\mathrm{m}, \mathrm{m}]$} & {$[\mathrm{m}, \mathrm{m}]$} & {$[\mathrm{n}, \mathrm{m}]$} & {$[\mathrm{vh}, \mathrm{ah}]$} \\
\hline $\mathrm{F} 2$ & {$[\mathrm{n}, \mathrm{vl}]$} & - & {$[\mathrm{n}, \mathrm{vl}]$} & {$[\mathrm{n}, 1]$} & {$[\mathrm{n}, \mathrm{vl}]$} & {$[\mathrm{n}, \mathrm{ah}]$} & {$[\mathrm{n}, \mathrm{vl}]$} \\
\hline F3 & {$[\mathrm{n}, \mathrm{vl}]$} & {$[\mathrm{vh}, \mathrm{ah}]$} & - & {$[\mathrm{n}, \mathrm{m}]$} & {$[\mathrm{n}, \mathrm{m}]$} & {$[\mathrm{n}, \mathrm{vl}]$} & {$[\mathrm{n}, \mathrm{m}]$} \\
\hline $\mathrm{F} 4$ & {$[\mathrm{~m}, \mathrm{~m}]$} & {$[\mathrm{h}, \mathrm{ah}]$} & {$[\mathrm{m}, \mathrm{ah}]$} & - & {$[\mathrm{m}, \mathrm{m}]$} & {$[\mathrm{n}, \mathrm{vl}]$} & {$[\mathrm{m}, \mathrm{m}]$} \\
\hline F5 & {$[\mathrm{m}, \mathrm{m}]$} & {$[\mathrm{vh}, \mathrm{ah}]$} & {$[\mathrm{m}, \mathrm{ah}]$} & {$[\mathrm{m}, \mathrm{m}]$} & - & {$[\mathrm{n}, \mathrm{vl}]$} & {$[\mathrm{vh}, \mathrm{ah}]$} \\
\hline F6 & {$[\mathrm{m}, \mathrm{ah}]$} & {$[\mathrm{n}, \mathrm{ah}]$} & {$[\mathrm{vh}, \mathrm{ah}]$} & {$[\mathrm{vh}, \mathrm{ah}]$} & {$[\mathrm{vh}, \mathrm{ah}]$} & - & {$[\mathrm{vh}, \mathrm{ah}]$} \\
\hline F7 & {$[\mathrm{n}, \mathrm{vl}]$} & {$[\mathrm{vh}, \mathrm{ah}]$} & {$[\mathrm{m}, \mathrm{ah}]$} & {$[\mathrm{m}, \mathrm{m}]$} & {$[\mathrm{n}, \mathrm{vl}]$} & {$[\mathrm{n}, \mathrm{vl}]$} & - \\
\hline
\end{tabular}

Table 3 The scale for linguistic terms

\begin{tabular}{lllllll}
\hline Absolutely low $(\mathrm{n})$ & Very low $(\mathrm{vl})$ & Low $(\mathrm{l})$ & Medium $(\mathrm{m})$ & High $(\mathrm{h})$ & Very high $($ vh) & Absolutely high $(\mathrm{ah})$ \\
\hline 0 & 1 & 2 & 3 & 4 & 5 & 6 \\
\hline
\end{tabular}

where $p_{i j}^{k}$ shows the degree of preference of the alternative $x_{i}$ over $x_{j}$ according to expert $e_{k}$. In this step, the preference matrix is constructed for the criteria.

Step 3 Transform the preference relations into HFLTS by using the transformation function $E_{G_{H}}$. For each HFLTS obtain an envelope $\left[p_{i j}^{k-}, p_{i j}^{k+}\right]$.

Step 4 Obtain the pessimistic and optimistic collective preference relations $\left(P_{C}^{-}\right.$and $\left.P_{C}^{+}\right)$. Compute the pessimistic and optimistic collective preference for each alternative using 2tuple sets. The 2-tuple set associated with $S$ is defined as $S=S \times[0.5,0.5)$. The function $\Delta:[0, g] \rightarrow S$ is given in Eq. (21).

$\Delta(\beta)=\left(s_{i}, \alpha\right)$ with $\left\{\begin{array}{l}i=\operatorname{round}(\beta) \\ \alpha=\beta-i\end{array}\right.$, where round assigns to $\beta$ the integer number $i \in$ $\{0,1, \ldots, g\}$ closest to $\beta$ and $\Delta^{-1}: S \rightarrow[0, g]$ is defined as shown in Eq. (22).

$\Delta^{-1}\left(s_{i}, \alpha\right)=i+\alpha$

Step 5 Build a vector of intervals $V^{R}=\left(p_{1}^{R}, p_{2}^{R}, \ldots, p_{n}^{R}\right)$ of collective preferences for the alternatives $p_{i}^{R}=\left[p_{i}^{-}, p_{i}^{+}\right]$.

Step 6 Calculate the midpoints of the intervals and normalize the results in order to find the weights.

\section{Application of the HFLTS-based AHP method to performance evaluation}

The performance evaluation factors for the branches of an international cargo company operating in Turkey which has 
Table 4 Pessimistic and optimistic collective preferences for the evaluation factors

\begin{tabular}{|c|c|c|c|c|c|c|c|}
\hline Goal & $\mathrm{F} 1$ & $\mathrm{~F} 2$ & F3 & $\mathrm{F} 4$ & F5 & F6 & F7 \\
\hline \multicolumn{8}{|c|}{ Pessimistic collective preferences } \\
\hline F1 & - & $(\mathrm{h},-0.0)$ & $(1,0.33)$ & $(1,-0.0)$ & $(1,-0.0)$ & $(\mathrm{vl},-0.0)$ & $(\mathrm{m}, 0.33)$ \\
\hline $\mathrm{F} 2$ & $(\mathrm{vl},-0.33)$ & - & $(\mathrm{n}, 0.33)$ & $(\mathrm{vl}, 0.33)$ & $(\mathrm{vl}, 0.33)$ & $(\mathrm{n}, 0.33)$ & $(\mathrm{vl},-0.33)$ \\
\hline F3 & $(1,0.33)$ & $(\mathrm{m},-0.0)$ & - & $(\mathrm{n}, 0.33)$ & $(\mathrm{vl},-0.33)$ & $(1,-0.33)$ & $(1,-0.0)$ \\
\hline F4 & $(\mathrm{h},-0.33)$ & $(\mathrm{h},-0.33)$ & $(\mathrm{h},-0.0)$ & - & $(\mathrm{m},-0.33)$ & $(\mathrm{vl},-0.0)$ & $(\mathrm{m},-0.33)$ \\
\hline F5 & $(\mathrm{h},-0.33)$ & $(\mathrm{h},-0.33)$ & $(\mathrm{h},-0.0)$ & $(1,0.33)$ & - & $(\mathrm{vl}, 0.33)$ & $(\mathrm{m}, 0.33)$ \\
\hline F6 & $(\mathrm{m}, 0.33)$ & $(\mathrm{m},-0.0)$ & $(\mathrm{h},-0.33)$ & $(\mathrm{h},-0.0)$ & $(\mathrm{m}, 0.33)$ & - & $(h, 0.33)$ \\
\hline F7 & $(1,-0.33)$ & $(\mathrm{vh},-0.33)$ & $(1,-0.33)$ & $(1,-0.0)$ & $(1,-0.33)$ & $(\mathrm{vl},-0.33)$ & - \\
\hline \multicolumn{8}{|c|}{ Optimistic collective preferences } \\
\hline $\mathrm{F} 1$ & - & $(\mathrm{vh}, 0.33)$ & $(\mathrm{h},-0.33)$ & $(1,0.33)$ & $(1,0.33)$ & $(\mathrm{m},-0.33)$ & $(\mathrm{h}, 0.33)$ \\
\hline $\mathrm{F} 2$ & $(1,-0.0)$ & - & $(\mathrm{m},-0.33)$ & $(1,-0.0)$ & $(1,0.33)$ & $(\mathrm{m},-0.33)$ & $(1,0.33)$ \\
\hline $\mathrm{F} 3$ & $(\mathrm{~h},-0.33)$ & $(\mathrm{ah},-0.33)$ & - & $(1,-0.0)$ & $(1,-0.0)$ & $(1,0.33)$ & $(\mathrm{h}, 0.33)$ \\
\hline $\mathrm{F} 4$ & $(\mathrm{~h},-0.0)$ & $(\mathrm{vh}, 0.33)$ & $(\mathrm{ah},-0.0)$ & - & $(\mathrm{h},-0.33)$ & $(1,-0.0)$ & $(\mathrm{h},-0.0)$ \\
\hline F5 & $(\mathrm{h},-0.0)$ & $(\mathrm{vh},-0.33)$ & $(\mathrm{vh}, 0.33)$ & $(\mathrm{m}, 0.33)$ & - & $(\mathrm{m},-0.33)$ & $(\mathrm{h}, 0.33)$ \\
\hline F6 & $(\mathrm{vh},-0.0)$ & $(\mathrm{ah},-0.33)$ & $(h, 0.33)$ & $(\mathrm{vh},-0.0)$ & $(\mathrm{vh},-0.33)$ & - & $(\mathrm{vh}, 0.33)$ \\
\hline F7 & $(\mathrm{m},-0.33)$ & $(\mathrm{vh}, 0.33)$ & $(\mathrm{h},-0.0)$ & $(\mathrm{m}, 0.33)$ & $(\mathrm{m},-0.33)$ & $(1,-0.33)$ & - \\
\hline
\end{tabular}

about 1000 branches are classified under 7 main groups which can be explained as follows.

Operational factors ( $F 1)$ Branches' cargo operations consist of two major processes which are incoming and outgoing cargo processes. These processes consist of loading and unloading cargos, controlling, packaging, and picking up and delivering cargos in a timely manner.

Human resources related factors (F2) Human resources management is the function within a branch organization that focuses on evaluating staff's performance, timekeeping, and turnover rate. This process includes conducting job analyses, planning personnel needs, recruiting the right people for the job, orienting and training.

Financial factors (F3) Branches' objective for financial process is improving cash flows, budget planning, expense controlling and collecting cash from customers.

Customer relations related factors ( F4) Branches' staff must be especially helpful to customers and must satisfy the customer's needs. The cargo company has customer complaints management system and their branches must solve these complaints in a given time. Being helpful and giving right information to customers, to be reached by branch phone, providing delivery according to customer requests are some of the important points which determine the customer satisfaction level.

Sales and marketing related factors ( $F 5$ ) The cargo company has large sales teams and all branches' managers are also responsible for increasing revenue and organizing campaigns according to customer groups.

Safety and security related (F6) Branch managers have to provide an array of standard secure features. Vehicles have satellite communication and branches' managers can follow the status of the delivery people online. Branch employees who accept cargos at the customer's address or in the branch and deliver them should behave in accordance with the safety regulations, policies and procedures.

Cooperation with other units related factors (F7) All branches must strive to develop mutually rewarding relationships with its team members. Major service goal of the cargo company is to maintain its competitive presence in the minds of the consumers. Branch employees should conduct research with a coordinated system between branches in cases such as lost cargo, cargo without bar code, and cargo without owner.

The above-mentioned comprehensive factors cover the main processes of cargo branches and the related PIs for these factors need to be determined while measuring the performance. Evaluation of these factors reveals the relative importance of the performance measures and thus prioritizes the PIs. Figure 1 displays the hierarchy of MCDM model.

The semantics and syntax of the linguistic term set $S$ is defined as follows:

$S=\left\{\begin{array}{l}\text { absolutely low }(\mathrm{n}), \text { very low }(\mathrm{vl}), \text { low }(\mathrm{l}), \text { medium }(\mathrm{m}), \\ \text { high }(\mathrm{h}), \text { very high }(\mathrm{vh}), \text { absolutely high }(\mathrm{ah})\end{array}\right\}$. 
Table 5 Weights of the factors with respect to goal

\begin{tabular}{llllll}
\hline Factors & Linguistic intervals & Interval utilities & Midpoints & Weights & Rank \\
\hline F1 & {$[(1,0.44),[\mathrm{m}, 0.44)]$} & {$[2.44,3.44]$} & 2.943 & 0.140 & 4 \\
F2 & {$[(\mathrm{vl},-0.22),(1,0.33)]$} & {$[0.78,2.33]$} & 1.555 & 0.074 & 7 \\
F3 & {$[(1,-0.33),(\mathrm{m}, 0.33)]$} & {$[1.67,3.33]$} & 2.500 & 0.119 & 6 \\
F4 & {$[(\mathrm{m},-0.05),(\mathrm{h},-0.0)]$} & {$[2.95,4]$} & 3.473 & 0.165 & 3 \\
F5 & {$[(\mathrm{m}, 0.06),(\mathrm{h}, 0.22)]$} & {$[3.06,4.22]$} & 3.638 & 0.173 & 2 \\
F6 & {$[(\mathrm{m}, 0.61),(\mathrm{vh}, 0.0)]$} & {$[3.61,5]$} & 4.305 & 0.204 & 1 \\
F7 & {$[(1,0.06),(\mathrm{m}, 0.28)]$} & {$[2.06,3.28]$} & 2.668 & 0.127 & 5 \\
\hline
\end{tabular}

Three decision-makers (DM1,DM2 and DM3) who have at least 15 years of experience in cargo sector evaluate the factors on a pairwise basis. Table 1 presents the linguistic pairwise evaluations of the experts.

The obtained envelops of each HFLTS or the HFLTS intervals are given in Table 2 .

The scale given in Table 3 is assigned to linguistic terms and the pessimistic and optimistic collective preferences are calculated using 2-tuple operations. Table 4 presents the pessimistic and optimistic collective preferences for the evaluation factors.

The linguistic intervals are converted to interval utilities. Finally, midpoints of interval utilities are obtained and then the weights are obtained by normalizing those midpoints. Table 5 gives linguistic intervals of the criteria, interval utilities associated with them, midpoints and obtained weights of all 7 factors.

According to the results given in Table 5, safety and security related factors (F6) has the highest importance level followed by sales and marketing related factors (F5), customer relations related factors (F4), operational factors (F1), cooperation with other units related factors (F7), financial factors (F3) and human resources related factors (F2).

\section{Conclusion}

This study presents a fuzzy MCDM approach for analyzing and evaluating the factors affecting the performance of the branches of a cargo company. One of the important problems in performance evaluation is to prioritize the performance indicators. The main contribution of the presented methodology is that it enables to determine the relative importance of the factors used in performance evaluation based on the subjective judgements of decision-makers, which is one of the most important steps of performance evaluation studies. A hesitant fuzzy sets extension of AHP is proposed for determining the importance weights and prioritizing the factors used in the performance evaluation of the branches of a cargo company. The usage of hesitant fuzzy sets with AHP method provides an effective and successful approach since it can integrate uncertainty and ambiguity into the evaluation process based on subjective judgements. The presented approach allows the flexibility of adding or removing new factors according to the conditions of the organization, thus the model can be applied for performance evaluation problems in different sectors which can be considered as a further research. Another alternative for further research can be the integration of presented method with other MCDM methods and evaluating the performance of alternatives.

Open Access This article is distributed under the terms of the Creative Commons Attribution 4.0 International License (http://creativecomm ons.org/licenses/by/4.0/), which permits unrestricted use, distribution, and reproduction in any medium, provided you give appropriate credit to the original author(s) and the source, provide a link to the Creative Commons license, and indicate if changes were made.

\section{References}

1. Bartolacci MR, LeBlanc LJ, Kayikci Y, Grossman TA (2012) Optimization modeling for logistics: options and implementations. $\mathrm{J}$ Bus Logist 33(2):118-127

2. Simsek B, Tuysuz F (2015) Simulation approach for modeling and analyzing the technological transfer center in a cargo company. In: 2015 6th international conference on modeling, simulation, and applied optimization (ICMSAO), pp 1-6. IEEE

3. Domingues ML, Reis V, Macário R (2015) A comprehensive framework for measuring performance in a third-party logistics provider. Transp Res Proc 10:662-672

4. Islam DMZ, Meier JF, Aditjandra PT, Zunder TH, Pace G (2013) Logistics and supply chain management. Res Transp Econ 41(1):316

5. Hong J, Chin AT, Liu B (2004) Logistics outsourcing by manufacturers in China: a survey of the industry. Transp J 43(1):17-25

6. Prajogo D, Chowdhury M, Yeung AC, Cheng TCE (2012) The relationship between supplier management and firm's operational performance: a multi-dimensional perspective. Int J Prod Econ 136(1):123-130

7. Fu HP, Chang TH, Shieh L, Lin A, Lin SW (2015) Applying DEA-BPN to enhance the explanatory power of performance measurement. Syst Res Behav Sci 32(6):707-720

8. Rushton A, Croucher P, Baker P (2014) The handbook of logistics and distribution management: understanding the supply chain, 5th edn. Kogan Page Publishers, The Chartered Institute of Logistics and Transport, London 
9. Ozcan T, Tuysuz F (2016) Modified grey relational analysis integrated with grey dematel approach for the performance evaluation of retail stores. Int J Inf Technol Decis Mak 15(02):353-386

10. Chou TY, Hsu CL, Chen MC (2008) A fuzzy multi-criteria decision model for international tourist hotels location selection. Int J Hosp Manag 27(2):293-301

11. Kahraman C, Ruan D, Dogan I (2003) Fuzzy group decisionmaking for facility location selection. Inf Sci 157:135-153

12. Cagrı TA, Tuysuz F, Kahraman C (2013) A fuzzy multi-criteria decision analysis approach for retail location selection. Int J Inf Technol Decis Mak 12(04):729-755

13. Kaya T, Kahraman C (2011) Fuzzy multiple criteria forestry decision making based on an integrated VIKOR and AHP approach. Expert Syst Appl 38(6):7326-7333

14. Zadeh LA (1965) Fuzzy sets. Inf Control 8(3):338-353

15. Kayakutlu G, Buyukozkan G (2011) Assessing performance factors for a 3PL in a value chain. Int J Prod Econ 131(2):441-452

16. Zhang J, Tan W (2012) Research on the performance evaluation of logistics enterprise based on the analytic hierarchy process. Energy Proc 14:1618-1623

17. Shaik MN, Abdul-Kader W (2014) Comprehensive performance measurement and causal-effect decision making model for reverse logistics enterprise. Comput Indus Eng 68:87-103

18. da Silveira Guimarães JL, Salomon VAP (2015) ANP applied to the evaluation of performance indicators of reverse logistics in footwear industry. Proc Comput Sci 55:139-148

19. Kucukaltan B, Irani Z, Aktas E (2016) A decision support model for identification and prioritization of key performance indicators in the logistics industry. Comput Hum Behav 65:346-358

20. Özceylan E, Çetinkaya C, Erbaş M, Kabak M (2016) Logistic performance evaluation of provinces in Turkey: a GIS-based multi-criteria decision analysis. Transp Res Part A Policy Pract 94:323-337

21. Posset M, Gronalt M, Hauslmayer H (2010) COCKPIIT-Clear operable and comparable key performance indicators for intermodal transportation. Study as an Annex to the Final Project Report, Wien

22. Torra V (2010) Hesitant fuzzy sets. Int J Intell Syst 25(6):529-539

23. Saaty TL (1980) The analytic hierarchy process. McGraw Hill, New York

24. Torra V, Narukawa Y (2009) On hesitant fuzzy sets and decision. In: IEEE international conference on fuzzy systems, 2009. FUZZIEEE 2009, pp 1378-1382. IEEE

25. Saaty TL, Vargas LG (2012) The seven pillars of the analytic hierarchy process. In: Models, methods, concepts \& applications of the analytic hierarchy process. Springer, US, pp 23-40

26. Xu Z, Liao H (2014) Intuitionistic fuzzy analytic hierarchy process. IEEE Trans Fuzzy Syst 22(4):749-761
27. Leung LC, Cao D (2000) On consistency and ranking of alternatives in fuzzy AHP. Eur J Oper Res 124(1):102-113

28. Wang TC, Chen YH (2008) Applying fuzzy linguistic preference relations to the improvement of consistency of fuzzy AHP. Inf Sci 178(19):3755-3765

29. Rodriguez RM, Martinez L, Herrera F (2012) Hesitant fuzzy linguistic term sets for decision making. IEEE Trans Fuzzy Syst 20(1):109-119

30. Mousavi SM, Gitinavard H, Siadat A (2014) A new hesitant fuzzy analytical hierarchy process method for decision-making problems under uncertainty. In: 2014 IEEE international conference on industrial engineering and engineering management (IEEM), pp 622-626. IEEE

31. Zhu B, Xu Z (2014) Analytic hierarchy process-hesitant group decision making. Eur J Oper Res 239(3):794-801

32. Zhu B, Xu Z, Zhang R, Hong M (2016) Hesitant analytic hierarchy process. Eur J Oper Res 250(2):602-614

33. Öztaysi B, Onar SÇ, Boltürk E, Kahraman C (2015) Hesitant fuzzy analytic hierarchy process. In: 2015 IEEE international conference on fuzzy systems (FUZZ-IEEE), pp 1-7. IEEE

34. Onar SÇ, Büyüközkan G, Öztayşi B, Kahraman C (2016) A new hesitant fuzzy QFD approach: an application to computer workstation selection. Appl Soft Comput 46:1-16

35. Zhou W, Xu Z (2016) Asymmetric hesitant fuzzy sigmoid preference relations in the analytic hierarchy process. Inf Sci 358:191207

36. Rodriguez RM, Martinez L, Herrera F (2012) Hesitant fuzzy linguistic term sets for decision making. IEEE Trans Fuzzy Syst 20(1):109-119

37. Rodríguez RM, Martinez L, Herrera F (2013) A group decision making model dealing with comparative linguistic expressions based on hesitant fuzzy linguistic term sets. Inf Sci 241:28-42

38. Yavuz M, Oztaysi B, Onar SC, Kahraman C (2015) Multicriteria evaluation of alternative-fuel vehicles via a hierarchical hesitant fuzzy linguistic model. Expert Syst Appl 42(5):2835-2848

39. Li D, Zeng W, Li J (2015) New distance and similarity measures on hesitant fuzzy sets and their applications in multiple criteria decision making. Eng Appl Artif Intell 40:11-16

40. Wang H, Xu Z (2016) Total orders of extended hesitant fuzzy linguistic term sets: definitions, generations and applications. Knowl Based Syst 107:142-154

41. He Y, Xu Z, Gu J (2016) An approach to group decision making with hesitant information and its application in credit risk evaluation of enterprises. Appl Soft Comput 43:159-169 